\title{
Education quality as a factor of modern student's social success
}

\author{
Elena Razinkina ${ }^{1}$, Ludmila Pankova ${ }^{1}$, Elena Pozdeeva $^{1}$, Lidiya Evseeva ${ }^{1}$, and Anna \\ Tanova ${ }^{1, *}$ \\ ${ }^{1}$ Peter the Great St. Petersburg Polytechnic University, 29, Polytechnicheskaya, 195251, St.- \\ Petersburg, Russia
}

\begin{abstract}
Rapidly growing educational space as well as increasing demands of the market to the modern specialist made the problem of social success a topical one. The paper focuses on sociological analysis of social success of students, its purpose is to study satisfaction with the quality of education obtained as a factor of their social success achieved in the educational process. Social success is regarded as integrated evaluation of student personality, which is based on analysis of the educational organization. In contrary, social unsuccess is connected with academic, professional and personal failure demonstrated in the process of student's self-realization in educational environment. Among factors, influencing the quality of education and hence the social success of students one can note motivation, professional focus, activity, digital behavior, skills in adopting of digital educational environment. Researches in this sphere can focus on development of feedback mechanisms with students, which can form their analytical competencies and foster confidence between participants of educational process. This determines to put focus of the study on resilient educational environment, project and creative forms of academic activity and on looking for the best ways of further implementation of digital technologies.
\end{abstract}

\section{Introduction}

The modern social environment, saturated with dynamic processes and flexibly changing under the influence of the infosphere $[1,2]$, makes us constantly re-evaluate the qualitative parameters of development, look for new factors and indicators. Education as a leading link in social development, along with science, acts in this connection as the main area of research, since the quality of the emerging potential of human resources and the future of society itself depend on the level of education and its trends. Qualitative parameters of education are at the epicenter of the attention of researchers and practitioners both from the standpoint of a systematic approach (management of the educational sphere) and from the sociological point of view - the identification of students' expectations, their motivation, activity, level of competencies, the formation of life trajectories after graduation. An important problem in the context of increasing the complexity of educational systems as a

\footnotetext{
*Corresponding author: tanovaann@mail.ru
} 
result of the increasing inclusion of electronic information technologies (e-learning) [3-6] and taking into account the implementation of the "life-long learning" paradigm is the achievement of a corridor for the success of students encompassing school and university levels. At the heart of the problematization is the student's social success as a criterion for achieving his life goals and plans, which is reflected in his satisfaction with learning and in his active role in the educational process. Achieving high quality learning indicators in the context of the education system's transformation, ongoing reforms and an emphasis on project breakthroughs provides the basis for the formation of students' social success, serves as a factor in adequately assessing the graduate's prospects in a dynamic market environment and is a pillar of building strategic goals.

The methodological basis of the study is the analysis of the pedagogical side of the education quality, which allows us to consider it as a factor in the social success of students, the parameters of which reflect sociological monitoring of students' satisfaction with the quality of educational programs implemented at the university. The student's social success is revealed by such indicators of sociological monitoring as: overall satisfaction with education and specific blocks of the educational program, justification of students' expectations in relation to their specialty and training, intention to work according to their specialty after graduation, assessment of the adequacy of knowledge and practical skills for future employment, assessment of the range of competencies acquired at the university, and the need for additional knowledge, assessment of the level of creativity and scientific component as elements of learning. The dynamics of satisfaction with the quality of education at a university is the basis for designing a system for managing the social success of students at a university.

Recently, the quality of education is being studied from the perspective of analyzing the ranking of universities, development of education quality assessment systems [7], compliance with international quality standards. As a multidimensional concept, the quality of education is considered as a comprehensive characteristic of the university, based on public recognition of the level of academic and scientific work, the competence of the teaching staff, the availability of a modern material and technical base and the demand for graduates in the labor market [8]. The system of components of the quality of education distinguishes: the quality of students, the quality of the teaching staff, the quality of university management and the quality of the educational environment [9]. Achieving high indicators of education quality ensures the achievement of the goal - the formation of graduate competencies that meet market expectations at the stage of transition to a new technological structure, which is especially important for technical universities [10].

According to students, one of the most important parameters of the quality of education is the competence of the teacher. Students attach paramount importance to the expert knowledge of the teacher, his pedagogical skills and behavioral aspects (self-regulation, stress tolerance and the ability to resolve conflict situations) [11]. A key role today is played by the teacher's ability to take into account changes in the conditions of the educational environment and choose adequate means to achieve educational and educational goals, taking into account the contingent, level of knowledge, general development and personal characteristics of students [12]. An integrated approach to the quality of education involves a process of continuous improvement of all components of the educational process in order to achieve effective results. From the pedagogical side, this requires forecasting the zone of potential development of students and constantly adjusting these forecasts taking into account individual characteristics of students and under the influence of external factors. From the standpoint of the educational system development, this requires an emphasis on the resilience of the educational environment, which makes it possible to forestall obstacles that arise, to experience difficulties with the least losses and violations of system and balance [13]. 
The consideration of social success as an indicator of the development of the student's personality, reflecting his self-esteem and at the same time the results of the activities of the educational organization, has become relevant recently. Student success, aimed at assessing the achievement of results, can be defined as an integral student's assessment of his own activities result effectiveness, which has received recognition from others. It is important to consider the emotional state, which expresses the student's personal positive attitude to activities [14], allowing him to feel his own satisfaction.

In contrast, social failure is interpreted as a qualitative characteristic of students' educational activities, reflecting the degree of discrepancy between the personal achievements of students and the socially significant results of their activities in higher education. At the same time, educational failure integrates the manifestations of educational, vocational-orientation and personal failure in the field of education [15].

Learning failure can be the result of insufficiently formed motivation in the context of real educational activity. This is the case if students do not have a clear understanding of educational activities at the university as a type of work that requires intellectual effort, hard work on oneself, systematic goal-setting and planning. According to a study by S. Reznik, only $31 \%$ of university students have a high level of educational motivation, while $24 \%$ have low or no motivation to learn. Only a quarter of students study without skipping classes, and they are keen on scientific research, and $10 \%$ of students participate in research. Many students associate problems in the learning process with the difficulties of the study itself $(37 \%)$, with adaptation $(32 \%)$, communication problems with teachers $(18 \%)$ and with peers $(13 \%)$. This indicates that a significant part of young people is not ready for the student's social role [16]. This suggests a connection between readiness for a student role, to study at a university, and the subsequent social success of a student.

Features of the digital learning environment of students also play a role in the process of shaping social success $[17,18,19]$. On the subject-technical side, the new digital generation of students has a number of characteristics [20], among which the following have a significant place:

1) a high degree of " equipping with devices" of students. All students often have at their disposal several devices (smartphone, tablet, gamepad, laptop, smart watches, etc.);

2) the wide distribution of various widgets (weather, hours, currency rates, traffic jams, Vkontakte, Facebook, "Tweet" buttons, etc.), which significantly reduce the time for searching for information;

3) a large selection of competing Internet providers, providing not only wireless Internet, but also hosting. This provides the student with constant access to the Internet, mail, databases and other widgets.

This forms the specifics of the digital behavior of students, the specific properties of which can be called the following:

- The illusion of multitasking. More than two thirds of students at the same time keep notes, listen to the teacher and work with visual information. However, it has been found that chronic multitaskers are less effective than those who resort to this method only occasionally;

- Network thinking. Signs of network thinking also include the widespread use of hyperlinks, which allow a deeper insight into the essence of the problem under study. Network thinking is an example of a new way of performing mental operations when an integral cognitive fragment is formed from an unrelated set of different information [21];

- Clip thinking. The owner of clip thinking operates only with meanings of a fixed length and cannot work with semiotic structures of arbitrary complexity. Outwardly, this manifests itself in the fact that the student cannot focus on any information for a long time, and his ability to analyze is reduced [22]; 
- "Google Effect" (or cataloging memory). Active users of search engines often remember the way how to get to the desired content, and not the content itself;

- A high level of cultural practices [23], digital behavior and interaction diversity (selfbranding, creating backups in the Cloud, online training, online banking, consulting, freelancing, etc.), which often generates forms of deviant behavior (bullying, trolling, etc.). This poses a threat to personal safety [18];

- Online education. The attitude of students to online courses that are being actively introduced today is quite interested and positive.

Among the observed consequences and risks of educational failure today there are such problematic phenomena as imitation of educational effectiveness, significant dropout rates at technical universities [24], academic fraud (plagiarism, use of laboratory, control writing services in the market) graduation), brain drain, subsequent deprofessionalization in the labor market and erosion of professional competencies.

Understanding students about the risks of the educational environment that they may face and expect is an important aspect of education quality management. On the basis of sociological studies of students' opinions [25], three blocks of risks were identified:

1. Social unit: loss of cultural traditions and familiar social norms, the formation of negative patterns of aggressive behavior, extremist ideology [26, 27].

2. Motivation unit: lack of motivation in choosing a profession, unclear idea of it, insufficient motivation for personal and professional self-realization [28], low level of selfunderstanding. This correlates with low cognitive activity, poorly formed training skills, stress and emotional tension, as well as with the problem of professional self-realization after graduation.

3. Organizational unit: isolation of learning from real life, high academic workloads, inconvenient schedule.

Reducing the risks of transition to a digital economy is seen on the basis of the key competencies formation of graduates. There are eight such competencies [8]: the ability to process large amounts of information, the ability to prioritize, understand the structure of one's own knowledge and skills and satisfy one's need for self-development, the ability to anticipate the development of a situation and determine the most promising preventive actions, abilities creativity, research competence, ability to self-development and flexible adaptability, communicative and managerial competence.

The quality of education and the trust associated with it can be considered as factors in overcoming the social failure of students in the educational environment. Sociologists revealed a correlation between students' trust in university teachers and their motivation for educational and research activity [29]. Underestimation of trusting relationships between participants in the educational process, based on horizontal connections, leads to increased destructive functions and a decline in the social effectiveness of higher education.

\section{Methods}

The study relies on a systematic approach to learning as a purposeful, systematically organized, controlled process of interaction between a teacher and a student, which involves the transfer of socio-cultural experience, the acquisition of competencies, the satisfaction of needs and the development of the personal potential of participants. The environmental approach used in the study allows us to analyze the dynamics and changes in the object of study under the influence of the external and internal environment factors. In this study, the educational environment of the university creates the necessary conditions for maintaining and developing the quality characteristics of education, determines and supports the impulses of new trends that arise in the process of self-organization and 
management, which allows you to track the impact of the education quality on the dynamism of student success.

The study uses a comparative approach, which allows to compare the students' prevailing expectations and learning outcomes. Based on the comparison, an idea of the student's social success is formed.

The aim of the study is to consider satisfaction with the quality of education as a factor in the social success of students. To achieve the goal, the following tasks were solved: on the basis of identifying the basic essential features of social success, characterize students' satisfaction with learning, which creates the basis for the successful development of educational programs; identify the components of assessing the social success of students during a sociological survey conducted in the monitoring system; identify key factors affecting the quality elements of educational programs and prospects for increasing student success.

The leading method of empirical research of the education quality is sociological monitoring, on the basis of which an assessment of students' satisfaction with education and an idea of the success of mastering educational programs are formed, reflecting such aspects of success as educational, communicative, creative, personal, professional. An additional component is the survey data related to the implementation of educational trends related to digitalization, the communicative space of the university, and the attitude to the educational environment of the university.

\section{Results}

From May 30 to June 30, 2019, in Peter the Great St. Petersburg Polytechnic University (SPbSTU) sociological monitoring of student satisfaction with the quality of mastering basic educational programs was conducted. The survey involved 3878 students. The total population is 21,490 people (students from the first to the sixth year of undergraduate, specialty and master's courses full-time studies). The quota sample is proportional, the confidence probability is $95 \%$, the sampling error (confidence interval) is $1.42 \%$.

The data from the monitoring survey allow us to establish that students demonstrate a rather high level of overall satisfaction with their education - 72\% (the answers are "completely satisfied" and "rather satisfied") (see Fig. 1).

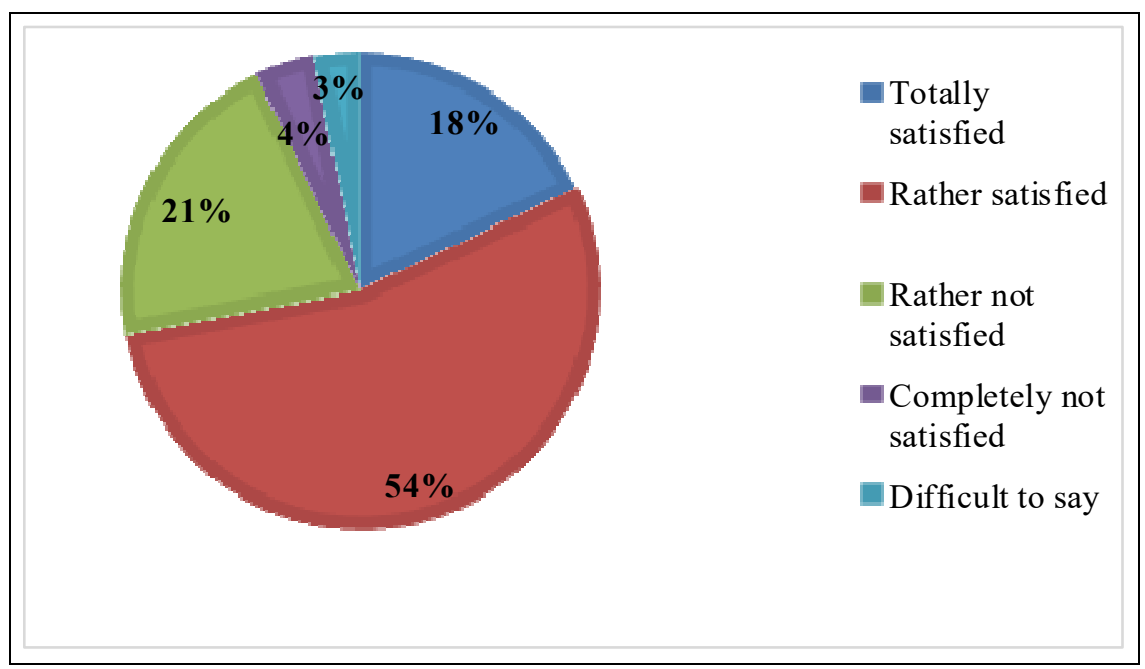

Fig. 1. Student satisfaction with the quality of education, obtained at SPbPU. 
The degree of students' satisfaction with the acquired knowledge and skills in separate blocks of disciplines - computer technology, foreign languages, general professional disciplines, profile / specialization disciplines, physical education, natural science and socio-humanitarian disciplines was also evaluated. To the question "Evaluate the degree of your satisfaction with the acquired knowledge and skills in the following blocks of disciplines" (on a five-point scale, where 0 - I find it difficult to answer, 1 - not at all satisfied, 5 - absolutely satisfied), the following answers were received: (see Fig. 2, $3,4,5,6,7,8)$.

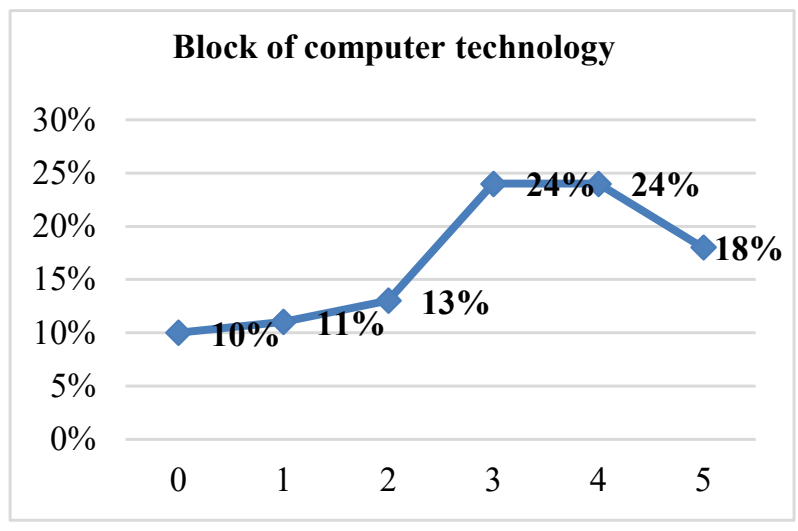

Fig. 2. Student satisfaction with the computer technology.

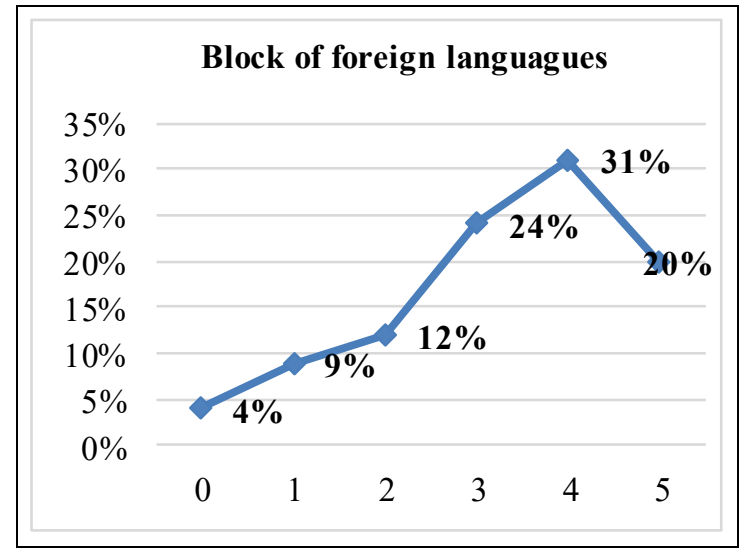

Fig. 3. Student satisfaction with the foreign languages. 


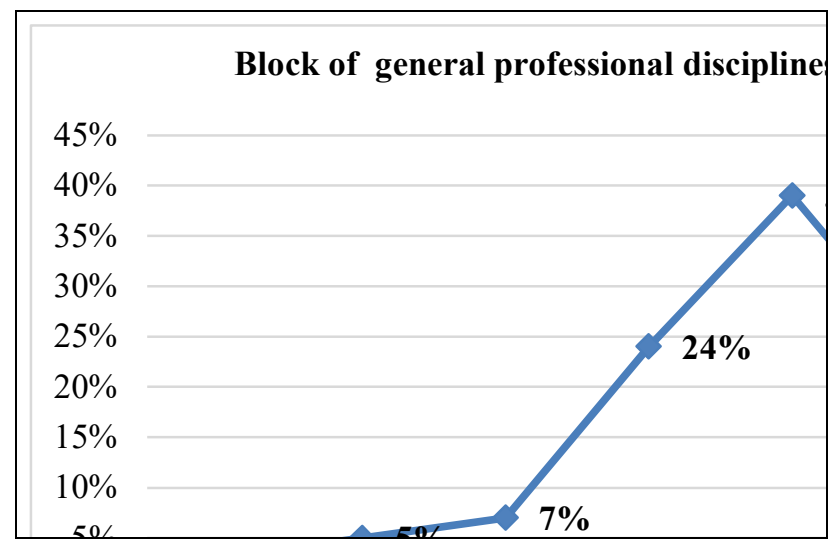

Fig. 4. Student satisfaction with the general professional disciplines.

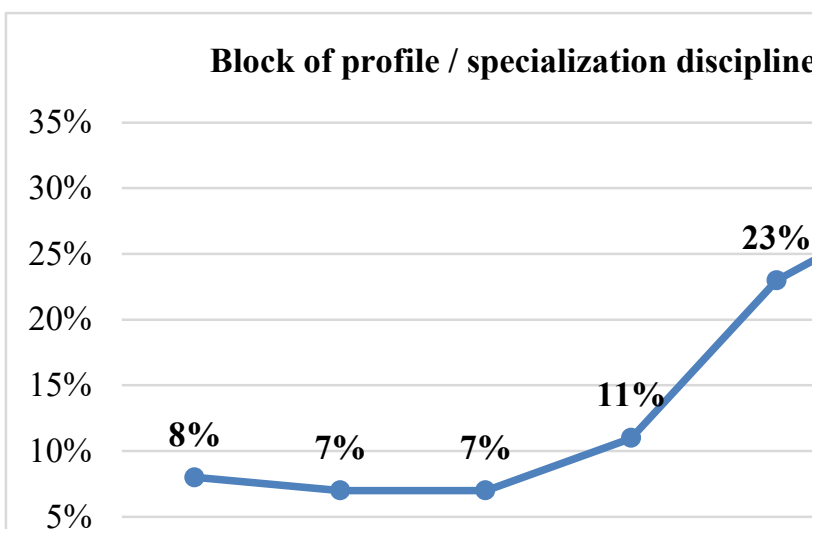

Fig. 5. Student satisfaction with the profile / specialization disciplines.

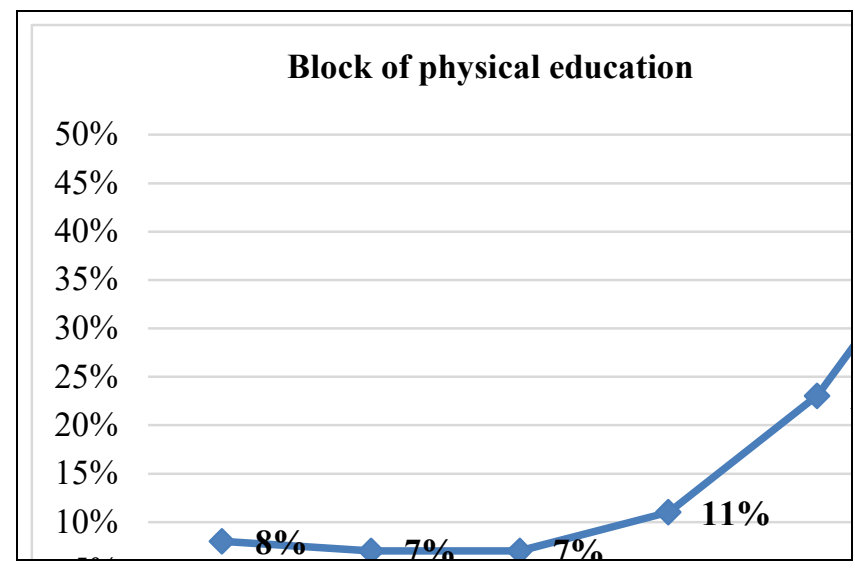

Fig. 6. Student satisfaction with the physical education. 


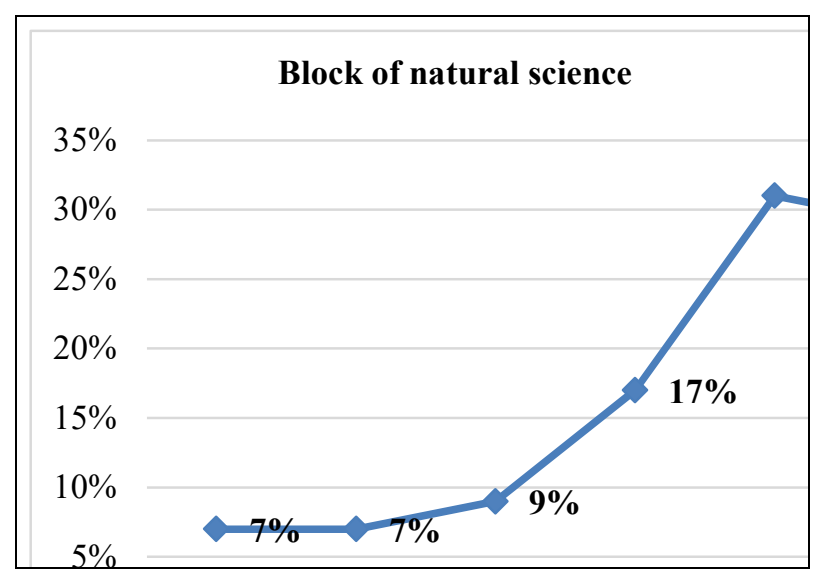

Fig. 7. Student satisfaction with the natural science.

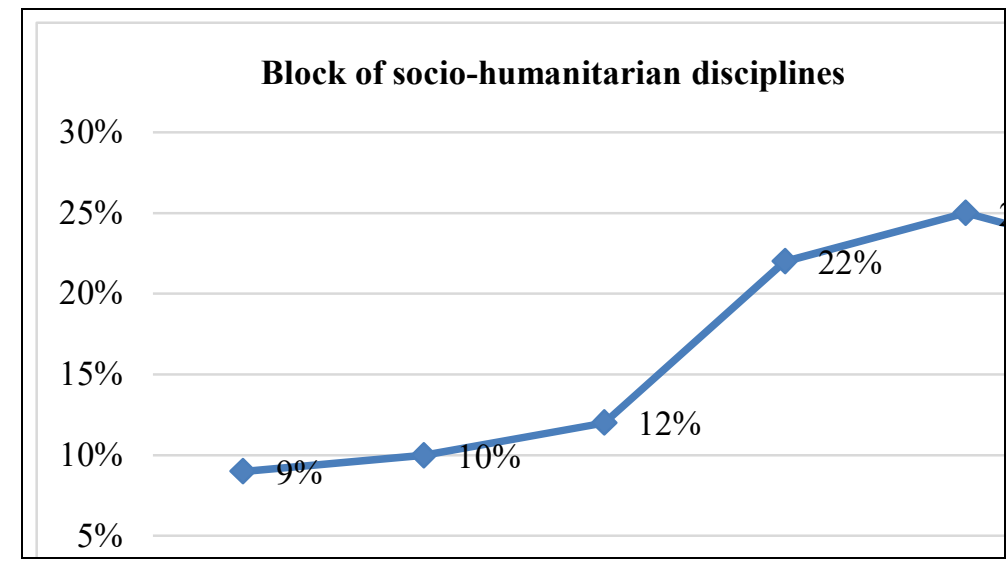

Fig. 8. Student satisfaction with the socio-humanitarian disciplines.

Students demonstrated a high degree of satisfaction with the blocks of general professional disciplines ( $61 \%$ of the grades " 4 " and " 5 " on a five-point scale), science and physical disciplines $(60 \%$ each). Slightly less respondents are satisfied with the disciplines of the profile (specialization) (54\% of the grades " 4 " and " 5 "), foreign languages $(51 \%)$ and the block of socio-humanitarian disciplines $(47 \%)$. The least degree of satisfaction was demonstrated with respect to the block of computer technologies $(42 \%)$. The physical education unit rated at " 5 " the largest number of students $-44 \%$.

According to the following indicator of the student's social success - justification of expectations from the obtained specialty / profile training - the following results were obtained: expectations were met more than half of the respondents $-54 \%, 16 \%-$ no, $30 \%$ found it difficult to answer (see Fig. 9). 


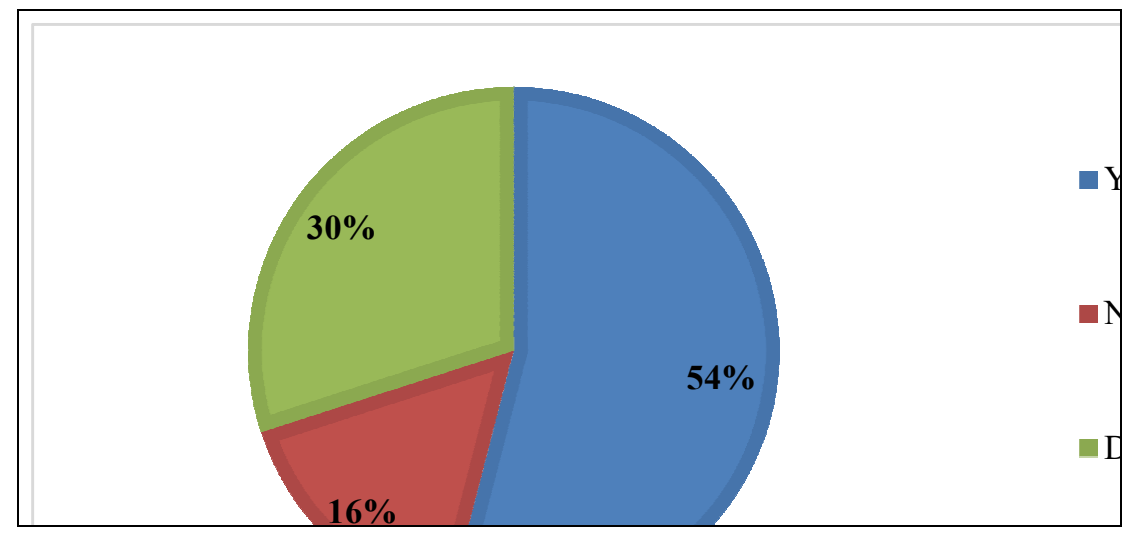

Fig. 9. Justification of expectations from the obtained specialty / profile training.

An equally important criterion for the social success of a student is his intention to work in his specialty. The majority of SPbPU students surveyed - 64\% - are going to work after graduating from the university to sphere of specialty acquired at the university (see Fig. $10)$.

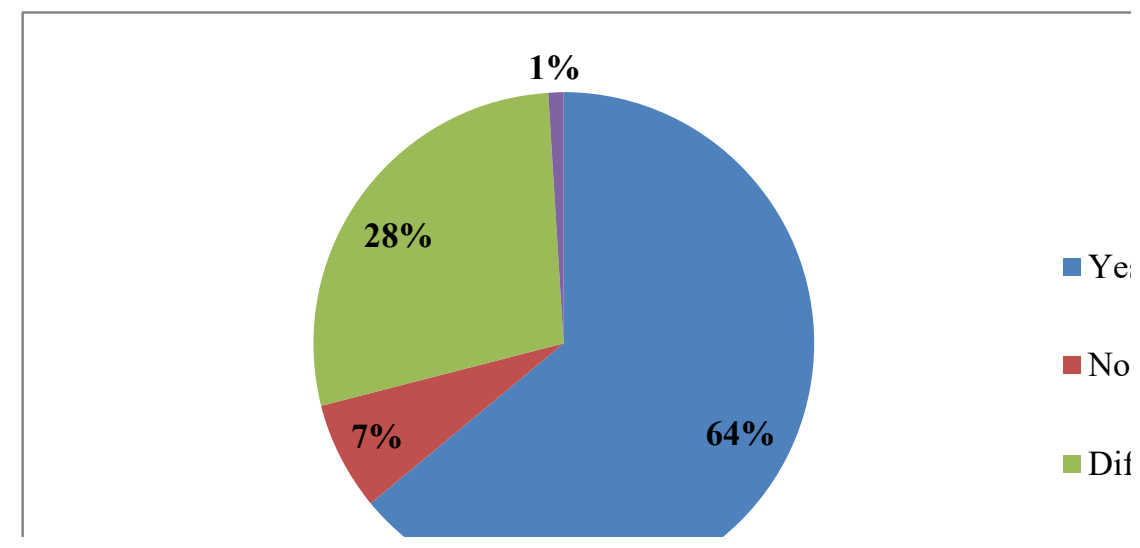

Fig. 10. Students going to work after graduating from the university.

The need for additional knowledge and skills also characterize a socially successful student. Among the students of SPbPU, foreign languages take first place in popularity in a row - $67 \%$ have chosen them, $50 \%$ are interested in computer technology, $49 \%$ are ready to study more professional disciplines, $33 \%$ would like to delve into the basics of psychology, $29 \%$ choose PR, advertising and marketing and $24 \%$ are interested in economics, management and accounting (see Fig. 11). 


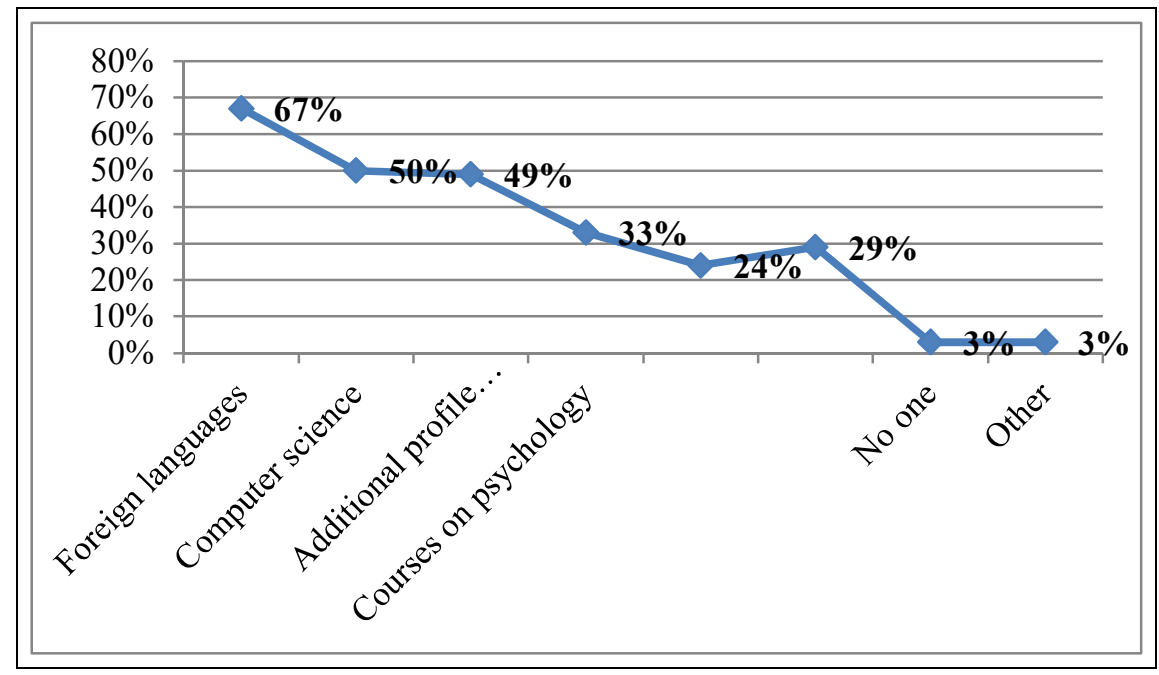

Fig. 11. Additional knowledge and skills, which may be useful for you (You may choose several answers).

Almost half of the respondents (48\%) agreed that the student's research activity is a necessary component of the learning process at the university. This demonstrates the need to popularize scientific activity among university students, to demonstrate that a socially successful student is not only one that is focused on practical professional activity, but also one who is attracted to scientific activity (see Fig. 12).

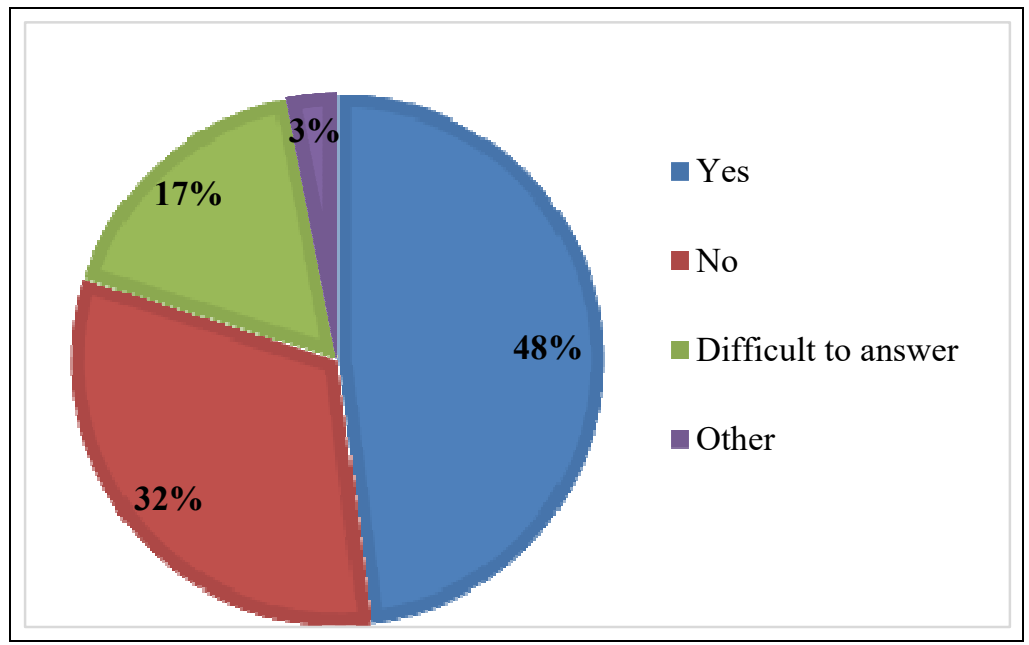

Fig. 12. Do you agree, that the student's research activity is a necessary component of the learning process at the university?

\section{Discussion and conclusions}

The results of the study indicate that in the face of increasing market requirements for university graduates, it is necessary to focus on factors that increase the social success of students, conduct monitoring of the education quality, reflecting the current state of their satisfaction and possible prospects. Identified parameters of the education quality affect the perception of the success of students' knowledge, skills and competencies development. In 
this regard, the student's achieved analytical competencies also increase, which allow them to evaluate their skills in the field of training, to build an individual educational trajectory aimed at successful professional activities. Today, an important resource is distance learning, helping the student to be included in the educational process not only during the period of study at the university, but also after graduation, realizing the paradigm of "lifelong learning". As the monitoring experience shows, it is the blended learning process that combines the advantages of traditional and online learning that is the most acceptable form of organization of the educational process at the modern university for students. The social success of a student depends on the degree of his satisfaction with the quality of the educational process organization, communicative practices with the teaching staff, the degree of mastering of work skills in the electronic educational environment. Peter the Great Polytechnic University confidently demonstrates quite high students' satisfaction with the quality of education, which means that students have all the opportunities to actively act in the educational, scientific, creative, creative components of the educational process for the most complete self-realization, leading to social success.

To conclude, it should be noted that the quality of education in a modern university is a key factor in the formation of students' competencies as an important tool for achieving social success. The educational trend towards a smart university lies along the path of creating the most favorable conditions for the formation of a new type of specialists for whom social success has become a key guideline. The results of a sociological study demonstrate the stable satisfaction of students with the quality of education, which allows us to see a positive response to the demands of the digital environment for a graduate as a socially successful agent of the modern economy.

\section{References}

1. O. Shipunova, L. Evseeva, E. Pozdeeva, V.V. Evseev, I. Zhabenko, E3S Web of Conferences 110, 02011 (2019) https://doi.org/10.1051/e3sconf/201911002011

2. D.S. Bylieva, V.V. Lobatyuk, A.V. Rubtsova, IOP Conference Series: Earth and Environmental Science 337, $012054 \quad$ (2019) https://doi.org/10.1088/17551315/337/1/012054

3. I. Zakharova, A. Kobicheva, N. Rozova, Education Sciences J. 9(3), 168 (2019) https://doi.org/10.3390/educsci9030168

4. N.N. Pokrovskaia, M.Yu. Ababkova, D.A. Fedorov, Education Sciences J. 9(3), 183 (2019) https://doi.org/10.3390/educsci9030183

5. L.I. Evseeva, O.D. Shipunova, E.G. Pozdeeva, I.R. Trostinskaya, V.V. Evseev, DSIC 2019. Advances in Intelligent Systems and Computing AISC 1114, 241-251 (Springer, Cham, 2020) https://doi.org/10.1007/978-3-030-37737-3_22

6. T.A. Baranova, A.M. Kobicheva, E.Y. Tokareva, ACM International Conference Proceeding Series, 77-81 (2019) https://dl.acm.org/doi/10.1145/3369199.3369245

7. E.M. Razinkina, K.V. Raev, O.V. Kalinina, St. Petersburg State Polytechnical University Journal. Humanities and Social Sciences J. 10 (2), 112-122 (2019) DOI: 10.18721/JHSS. 10210

8. A.I. Rudskoy, A.I. Borovkov, P.I. Romanov, O.V. Kolosova, Higher education in Russia J. 28(2), 9-22 (2019) https://doi.org/10.31992/0869-3617-2019-28-2-9-22

9. F.L. Ratner, N.V. Tikhonova, Higher education in Russia J. 28 (12), $87-96$ (2019) DOI: https://doi.org/10.31992/0869-3617-2019-28-12-87-96

10. O.D. Shipunova, I.P. Berezovskaya, International Journal of Civil Engineering and Technology (IJCIET) J. 9(10), 2020-2028 (2018) 
11. M.A. Lukashenko, A.A. Ozhgikhina, Higher education in Russia J. 28 (1), 46-56 (2019) DOI: https://doi. org/10.31992/0869-3617-2019-28-1-46-56

12. D. Joulia, Cahiers de l'APLIUT J. XXII (1), 23-39 (2003) DOI: 10.4000/apliut.3977

13. E. Razinkina, L. Pankova, I. Trostinskaya, E. Pozdeeva, L. Evseeva, A. Tanova, E3S Web of Conferences 110, 02097 (2019) https://doi.org/10.1051/e3sconf/201911002097

14. A.S. Matveevskaya, V.L. Pogodina, T.S. Tarakanova, V.V. Evseev, I.E. Nesterova, International Journal of Civil Engineering and Technology (IJCIET) J. 9(10), 15661574 (2018)

15. G.E. Zborovsky, P.A. Ambarova, Bulletin of the Institute of Sociology J. 10(4), 126149 (2019) DOI: 10.19181/vis.2019.31.4.620

16. S.D. Reznik, M.V. Chernikovskaya, Integration of Education J. 23(1), $85-99$ (2019) DOI: 10.15507/1991-9468.094.023.201901.085-099

17. D. Bylieva, V. Lobatyuk, A. Safonova, A. Rubtsova, Education Sciences J. 9, 167 (2019) DOI: 10.3390/educsci9030167

18. O.D. Shipunova, E.G. Pozdeeva, V.V. Evseev, CSIS'2019: Proceedings of the XI International Scientific Conference Communicative Strategies of the Information Society 25, 1-6 (2019) https://doi.org/10.1145/3373722.3373792

19. T. Baranova, A. Kobicheva, E. Tokareva, DSIC 2019. Advances in Intelligent Systems and Computing, AISC 1114, 263-274 (Springer, Cham, 2020) DOI: https://doi.org/10.1007/978-3-030-37737-3_24

20. R.M. Petruneva, V.D. Vasilieva, Yu.V. Petruneva, Higher education in Russia J. 28 (11), 47-55 (2019) DOI: https://doi.org/10.31992/0869-3617-2019-28-11-47-55

21. D.S. Bylieva, V.V. Lobatyuk, T.A. Nam, IOP Conference Series: Earth and Environmental Science 337, 012048 (2019) https://doi.org/10.1088/1755$1315 / 337 / 1 / 012048$

22. O.D. Shipunova, L.V. Mureyko, V.A. Serkova, I.B. Romanenko, Yu.M. Romanenko, Indian Journal of Science and Technology J. 9(42), 383 (2016) DOI: 10.17485/ijst/2016/v9i42/104226

23. A.S. Matveevskaya, S.N. Pogodin, Vestnik Sankt-Peterburgskogo Universiteta, Filosofia i Konfliktologiia J. 33(1), 115-118 (2017) DOI: 10.21638/11701/spbu17.2017.112

24. A.F. Smyk, V.I. Prusova, L.L. Zimanov, A.A. Solntsev, Higher education in Russia J. 28 (6), 52-62 (2019) DOI: https://doi. org/10.31992/0869-3617-2019-28-6-52-62

25. A.V. Lyalyuk, O.R. Tuchina, Higher education in Russia J. 28 (11), 56-67 (2019) https://doi.org/10.31992/0869-3617-2019-28-11-56-67

26. A.S. Matveevskaya, S.N. Pogodin, Vestnik Sankt-Peterburgskogo Universiteta, $\begin{array}{lllll}\text { Filosofia i Konfliktologiia J. 34(1), } & \text { 17-23 }\end{array}$ DOI: $10.21638 / 11701 /$ spbu17.2018.110

(2018)

27. Y.V. Klyuev, D.V. Zubko, I.N. Blokhin, M.S. Petrova, A.M. Kuzmina, Man in India J. 97(22), 229-242 (2017)

28. O.E. Piskun, M.Y. Ababkova, V.L. Leontyeva, Teoriya i Praktika Fizicheskoy Kultury J. 10, 45-47 (2018)

29. G.E. Zborovsky, P.A. Ambarova, Sociological Journal J. 4, 93-112 (2018) https://doi.org/10.19181/socjour.2018.24.4.6099 